\title{
Matrix Metalloproteases 1 and 3 Promoter Gene Polymorphism Is Associated With Rotator Cuff Tear
}

\author{
Jorge H. Assunção MD, Alexandre L. Godoy-Santos PhD, \\ Maria Cristina L. G. dos Santos PhD, Eduardo A. Malavolta PhD, \\ Mauro E. C. Gracitelli PhD, Arnaldo A. Ferreira Neto PhD
}

Received: 17 October 2016/Accepted: 26 January 2017/Published online: 3 February 2017

(C) The Association of Bone and Joint Surgeons \& 2017

\begin{abstract}
Background Studies suggest that the collagen degeneration and disordered arrangement of collagen fibers in rotator cuff tears are associated with an increase in activity of matrix metalloproteases 1 and 3 (MMP-1 and MMP-3), and that MMP activity may be in part genetically mediated. The degree to which this might be clinically relevant in patients with rotator cuff tears has not been well characterized.
\end{abstract}

Each author certifies that neither he or she, nor any member of his or her immediate family, have funding or commercial associations (consultancies, stock ownership, equity interest, patent/licensing arrangements, etc) that might pose a conflict of interest in connection with the submitted article.

All ICMJE Conflict of Interest Forms for authors and Clinical Orthopaedics and Related Research ${ }^{\circledR}$ editors and board members are on file with the publication and can be viewed on request.

Clinical Orthopaedics and Related Research ${ }^{\circledR}$ neither advocates nor endorses the use of any treatment, drug, or device. Readers are encouraged to always seek additional information, including FDAapproval status, of any drug or device prior to clinical use.

Each author certifies that his or her institution approved the human protocol for this investigation, that all investigations were conducted in conformity with ethical principles of research, and that informed consent for participation in the study was obtained.

This work was performed at the Department of Orthopedics and Traumatology, University of São Paulo, São Paulo, Brazil.

J. H. Assunção ( $₫)$, A. L. Godoy-Santos, E. A. Malavolta, M. E. C. Gracitelli, A. A. Ferreira Neto

Department of Orthopedics and Traumatology, School of Medicine, University of São Paulo, Rua Dr. Ovídio Pires de Campos 333, 3rd Floor, Cerqueira Cesar, São Paulo, SP 05403010, Brazil

e-mail: drjorgeassuncao@gmail.com

M. C. L. G. dos Santos

Department of Cell Biology, University Federal of Paraná, Curitiba, Paraná, Brazil
Questions/purposes (1) Is genetic polymorphism of MMP-1 and MMP-3 associated with rotator cuff tears? (2) Are there haplotypes of MMP-1 and MMP-3 correlated with rotator cuff tears? (3) Compared with control subjects, do patients with rotator cuff tears have a higher proportion of relatives with the same disease?

Methods We evaluated 64 patients with full-thickness rotator cuff tears and 64 asymptomatic control subjects. Patients younger 65 years, with nontraumatic tears, were included. The tear or integrity of the rotator cuff tear was evaluated by MRI or ultrasonography in all individuals. The patients and control subjects were paired by age. MMP-1 and MMP-3 genotypes were determined using the PCR-restriction fragment length polymorphism assays.

Results Genetic polymorphisms in MMP-1 and MMP-3 are associated with rotator cuff tear, in which individuals with rotator cuff tears have associated genotypes $1 \mathrm{G} / 2 \mathrm{G}$ (patients, 32 of 64 [50\%], control subjects, 16 of 64 [25\%]; odds ratio [OR], 4.8; 95\% CI, 2.1-11.0; p < 0.001) and $2 \mathrm{G} / 2 \mathrm{G}$ were at great risk (patients, 15 of 64 [23\%], control subjects, seven of 64 [11\%]; OR, 5.2; 95\% CI,1.8-14.9; $\mathrm{p}<0.001$ ), and patients with rotator cuff tears were associated with a higher proportion of $2 \mathrm{G}$ allele distribution (62 of 128 [48\%] versus 30 of 128 [23\%]; $p<0.001$ ). Patients with the $5 \mathrm{~A} / 5 \mathrm{~A}$ genotype are at greater risk of rotator cuff tear (patients, 15 of 64 [23\%]; control subjects, four of 64 [6\%]; OR, 5.5; 95\% CI, 1.4-20.9; $\mathrm{p}=0.021$ ), and there was higher $5 \mathrm{~A}$ allele distribution in patients with rotator cuff tears (patients, 68 of 128 [53\%]; control subjects, 52 of 128 [41\%]; $\mathrm{p}=0.045)$. Individuals with the haplotype $2 \mathrm{G} / 5 \mathrm{~A}$ were more likely to have rotator cuff tears develop (patients, 42 of 64 [66\%]; control subjects, 17 of 64 [27\%]; OR, 5.3; 95\% CI, 2.5-11.3; p < 0.001). Patients with rotator cuff tears reported, in higher number, the existence of relatives who previously had treatment for 
rotator cuff tears (19 of 64 [30\%] versus four of 64 [6\%]; OR, 6.3; 95\% CI, 2.0-19.9; $\mathrm{p}=0.001$ ).

Conclusions The genetic polymorphism of MMP-1 and MMP-3 is associated with rotator cuff tear. Individuals with haplotype $2 \mathrm{G} / 5 \mathrm{~A}$ were more susceptible to rotator cuff tears in the population studied.

Clinical Relevance Knowledge of the genetic markers related to rotator cuff tears can enable identification of susceptible individuals and increase understanding of the pathogenesis of tendon degeneration.

\section{Introduction}

Tendon degeneration is mediated by matrix metalloproteases (MMPs), cytokines, and free radicals that act on the extracellular matrix, altering its composition and biomechanical properties [22]. MMPs are enzymes capable of degrading collagen fibers and other elements of the extracellular matrix [9]. MMP-1 is a protease that breaks down type I collagen fibers [28]. MMP-3 is involved in regulation and activation of the MMPs. In addition to this activity, MMP-3 is capable of degrading Types II, IV, V, IX, and X collagen, proteoglycans, fibronectin, and elastin [11]. The production and activation of the MMPs are induced by cytokines, growth factors, and cell-cell and cell-matrix interactions [9]. Some single nucleotide polymorphisms (SNPs) in the MMP gene promoter region are correlated with an increase in activity and production of these enzymes $[25,33]$. SNPs of MMP-1 and MMP-3 were previously correlated with tendinopathy of the posterior tibial tendon and the Achilles tendon [12, 31].

The etiology of a rotator cuff tear is a multifactorial process, and various extrinsic and intrinsic tendon factors have been proposed to explain it [20]. There is no consensus regarding the main factors, and there appears to be an interaction among them [7,22]. Extrinsic factors include bony impingement and morphologic variations in the coracoacromial arch such as a curved or hooked acromion and os acromiale [22]. Intrinsic factors include tendon degeneration, tissue hypovascularization, and local inflammatory responses $[22,41]$. In the pathogenesis of a rotator cuff tear, we found a decrease in synthesis and an increase in degradation of collagen fibers associated with an increase in activity of MMP-1 and MMP-3 $[6,13,27,40]$. There is evidence that genetic factors may be involved in the etiology of rotator cuff tears $[16,36]$. Recently, some SNPs were associated with tendinopathy or rotator cuff tear [17, 24, 37, 38]. However, we have not found any studies that exclusively evaluate the association of the genetic polymorphism of the MMPs and rotator cuff tears, despite the relevance of these enzymes in their pathophysiology.

Therefore, we asked: (1) Is genetic polymorphism of MMP-1 and MMP-3 associated with rotator cuff tears? (2) Are there haplotypes of MMP-1 and MMP-3 correlated with rotator cuff tears? (3) Compared with control subjects, do patients with rotator cuff tears have a higher proportion of relatives with the same disease?

\section{Materials and Methods}

We performed a case-control study with a ratio of one to one. We evaluated patients younger than 65 years who underwent repair of full-thickness rotator cuff tears at our institution between June 2014 and December 2015. Patients with rheumatologic disease, diabetes, previous shoulder surgeries, or previous or current infectious processes in this shoulder were excluded. Patients with traumatic rotator cuff tears also were excluded as were those with partial tears. The control group consisted of patients who were treated at the same hospital for traumatic disorders without symptoms of shoulder pain and clinical signs of rotator cuff disease. The patients and control subjects were paired by age with a maximum difference of \pm 2 years.

The patients and control subjects underwent rotator cuff imaging (MRI or ultrasonography). All control subjects had intact rotator cuff tendons. Patients with rotator cuff tears were evaluated by MRI. Among the controls subjects, 30 of $64(47 \%)$ underwent ultrasonography to assess the integrity of the rotator cuff, and MRI was the imaging method used in 34 of $64(53 \%)$. The tests were performed at our institution's radiology department by the same group of musculoskeletal radiologists (APB, COK, MBR).The study was approved by the local ethics committee. Informed consent was obtained from all patients and subsequently through interview the following data were collected from the patients: age, sex, ethnicity, smoking, presence of high blood pressure, hypothyroidism, tendinopathies in other joints, existence of relatives who previously had treatment for rotator cuff tears, sports with shoulder involvement, and work with repeated and sustained arm abduction.

We evaluated 128 patients, 64 with rotator cuff tears and 64 control subjects (Table 1). We had no loss of samples during the DNA extraction and genotyping. The patients with rotator cuff tears and the control subjects had a mean age of $54 \pm 6$ years and $53 \pm 6$ years, respectively $(\mathrm{p}=0.586)$. Of the patients who underwent rotator cuff repair, $44(69 \%)$ were females, and of the control subjects, $40(61 \%)$ were females $(\mathrm{p}=0.577)$. 
Table 1. Baseline demographic and clinical characteristics

\begin{tabular}{|c|c|c|c|}
\hline Characteristic & Patients & Control subjects & $\mathrm{p}$ Value \\
\hline Age (years) & $54 \pm 6$ & $53 \pm 6$ & 0.586 \\
\hline \multicolumn{4}{|l|}{ Sex } \\
\hline Male & $20(31 \%)$ & $24(37 \%)$ & \multirow[t]{2}{*}{0.577} \\
\hline Female & $44(69 \%)$ & $40(63 \%)$ & \\
\hline \multicolumn{4}{|l|}{ Ethnicity } \\
\hline White & $48(75 \%)$ & $45(70 \%)$ & \multirow[t]{2}{*}{0.692} \\
\hline Nonwhite & $16(25 \%)$ & $19(30 \%)$ & \\
\hline \multicolumn{4}{|c|}{ Other tendinopathies } \\
\hline Yes & $10(16 \%)$ & $2(3 \%)$ & \multirow[t]{2}{*}{0.016} \\
\hline No & $54(84 \%)$ & $62(97 \%)$ & \\
\hline \multicolumn{4}{|l|}{ Smoking } \\
\hline Yes & $9(14 \%)$ & $9(14 \%)$ & \multirow[t]{2}{*}{$>0.999$} \\
\hline No & $55(86 \%)$ & $55(86 \%)$ & \\
\hline \multicolumn{4}{|l|}{ Hypertension } \\
\hline Yes & $13(20 \%)$ & $15(23 \%)$ & \multirow[t]{2}{*}{0.831} \\
\hline No & $51(80 \%)$ & $49(77 \%)$ & \\
\hline \multicolumn{4}{|c|}{ Hypothyroidism } \\
\hline Yes & $1(2 \%)$ & $2(3 \%)$ & \multirow[t]{2}{*}{$>0.999$} \\
\hline No & $63(98 \%)$ & $62(97 \%)$ & \\
\hline \multicolumn{4}{|c|}{ Work with repeated and sustained arm abduction } \\
\hline Yes & $26(41 \%)$ & $23(36 \%)$ & \multirow[t]{2}{*}{0.716} \\
\hline No & $38(59 \%)$ & $41(64 \%)$ & \\
\hline \multicolumn{4}{|c|}{ Sports with shoulder involvement } \\
\hline Yes & $5(8 \%)$ & $8(12 \%)$ & \multirow[t]{2}{*}{0.560} \\
\hline No & $59(92 \%)$ & $56(88 \%)$ & \\
\hline
\end{tabular}

Continuous data $=$ means $\pm \mathrm{SD}$; categorical data $=$ number $(\%)$.

The groups did not differ regarding race, smoking, or the presence of high blood pressure $(p=0.692, p>0.999$, and $\mathrm{p}=0.831$, respectively). Tendinopathies in other joints were more prevalent among patients with rotator cuff tears $(\mathrm{p}=0.016)$.

DNA from epithelial buccal cells was extracted using the procedure described by Aidar and Line [2]. DNA concentration $(\mathrm{ng} / \mu \mathrm{L})$ was estimated by measurements of optical density 260/280 $\mathrm{nm}$ at a ratio greater than 1.9.

The SNPs were identified previously and included in the database of the National Center for Biotechnology Information (http://www.ncbi.nlm.nih.gov/SNP/) with minor allele frequencies greater than 0.2. The MMP genotypes were determined using the PCR-random fragment length polymorphism assays (Table 2).

PCR primers were done in a total volume of $15 \mu \mathrm{L}$ containing $100 \mathrm{ng}$ of genomic DNA, $8 \mu \mathrm{L}$ Taq Green (Amersham Pharmacia-Biotech, Uppsala, Sweden), and $200 \mathrm{nmol}$ of each primer. An $8-\mu \mathrm{L}$ aliquot of PCR products then was digested with 1 unit of specific enzyme overnight.
The total amount of aliquot of the digest was electrophoresed on $5 \%$ agarose at $20 \mathrm{~mA}$. The gel was stained by GelRed ${ }^{\mathrm{TM}}$ (Biotium Inc, Fremont, CA, USA).

The MMP-1 polymorphism at position -1607 (rs1799750) is characterized by the insertion a base guanine $(\mathrm{G})$, which results in two alleles: $1 \mathrm{G}$ and $2 \mathrm{G}$. The allele $2 \mathrm{G}$ is represented by the DNA of 118 base pairs and the allele $1 \mathrm{G}$ is represented by the DNA of 89 base pairs. The heterozygous genotype has a combination of both alleles.

The MMP-3 polymorphism (rs3025058) is characterized by the presence of five or six adenines in position -1612 , resulting in alleles $5 \mathrm{~A}$ and $6 \mathrm{~A}$. Allele $6 \mathrm{~A}$ is represented by a band of DNA with 129 base pairs and the allele 5A by 97 base pairs. The heterozygous genotype has a combination of both alleles.

The sample size calculation used a level of significance of 5\% and power of $80 \%$. At the time this research protocol was elaborated, there were no studies, to our knowledge, regarding the association between the genetic polymorphism of MMPs and rotator cuff tears. Using a rate of $25 \%$ of the allele 2G of MMP-1 in the control group [12], an expected difference of $25 \%$ between groups, and $10 \%$ loss of samples in the extraction and genotyping of the DNA, 64 individuals were required for each group.

\section{Statistical Analysis}

The normality of the data was tested using the ShapiroWilk test. All continuous variables were normally distributed. The continuous variables were presented as means and SD and the categorical variables as absolute value and percentage.

The comparison between the patients and control subjects, in relation to the different variables, was performed using chi-square or Fisher's exact tests in the categorical variables and Student's t text in the continuous variables.

The difference in frequency of the alleles and genotypes of MMP-1 and -3 was evaluated in patients with rotator cuff tears and control subjects by the chi-square test. The probability of an association with rotator cuff tear was calculated as the odds ratio (OR) for the different genotypes with a $95 \%$ confidence interval.

The program ARLEQUIN Version 2.0 (Laurent Excoffier CMPG, Institute of Ecology and Evolution, University of Bern, Bern, Switzerland) [34] was used for the analysis of Hardy-Weinberg equilibrium in the population studied. The distribution of genotypes of the study subjects was in the Hardy-Weinberg equilibrium. For the data analysis, we used SPSS ${ }^{\circledR}$ Version 21.0 (IBM Corp, Armonk, NY, USA) with a level of significance of $5 \%$. 
Table 2. PCR-RFLP conditions for MMP-1 (rs1799750) and MMP-3 (rs3025058) polymorphisms

\begin{tabular}{lllll}
\hline SNP & Primers (5'-3') & Annealing & RFLP & bp PCR-RFLP \\
\hline MMP-1 (rs1799750) & F: TCGTGAGAATGTCTTCCCATT & $55^{\circ} \mathrm{C}$ & XmnI & 118 (allele 2G) \\
& R: TCTTGGATTGATTTGAGATAAGTGAAATC & 30 seconds & $37^{\circ} \mathrm{C}$ & $89+29$ (allele 1G) \\
MMP-3 (rs3025058) & F: GGTTCTCCATTCCTTTGATGGGGGGAAAGA & $53^{\circ} \mathrm{C}$ & Tth111I & 129 (allele 6A) \\
& R: CTTCCTGGAATTCACATCACTGCCACCACT & 1 minute & $37^{\circ} \mathrm{C}$ & $97+32$ (allele 5A) \\
\hline
\end{tabular}

PCR-RFLP = polymerase chain reaction-restriction fragment length polymorphism; MMP = matrix metalloprotease; SNP $=$ single nucleotide polymorphism; $\mathrm{F}=$ primer forward; $\mathrm{R}=$ primer reverse; $\mathrm{bp}=$ base pairs.

Table 3. Distribution of the MMP-1 and MMP-3 genotypes and 2G/5A haplotype

\begin{tabular}{|c|c|c|c|c|}
\hline \multirow[t]{2}{*}{ Genotype } & \multirow[t]{2}{*}{ Patients } & \multirow[t]{2}{*}{ Control subjects } & \multicolumn{2}{|l|}{ Odds ratio } \\
\hline & & & $(95 \% \mathrm{CI})$ & $\mathrm{p}$ Value \\
\hline \multicolumn{5}{|l|}{ MMP-1 } \\
\hline $1 \mathrm{G} / 1 \mathrm{G}$ & $17(27 \%)$ & $41(64 \%)$ & Reference & \\
\hline $1 \mathrm{G} / 2 \mathrm{G}$ & $32(50 \%)$ & $16(25 \%)$ & $4.8(2.1-11.0)$ & \\
\hline $2 \mathrm{G} / 2 \mathrm{G}$ & $15(23 \%)$ & $7(11 \%)$ & $5.2(1.8-14.9)$ & $<0.001$ \\
\hline \multicolumn{5}{|l|}{ MMP-3 } \\
\hline $6 \mathrm{~A} / 6 \mathrm{~A}$ & $11(17 \%)$ & $16(25 \%)$ & Reference & \\
\hline $5 \mathrm{~A} / 6 \mathrm{~A}$ & $38(59 \%)$ & $44(69 \%)$ & $1.3(0.5-3.0)$ & \\
\hline $5 \mathrm{~A} / 5 \mathrm{~A}$ & $15(23 \%)$ & $4(6 \%)$ & $5.5(1.4-20.9)$ & 0.021 \\
\hline \multicolumn{5}{|c|}{ 2G/5A haplotype } \\
\hline No & $22(34 \%)$ & $47(73 \%)$ & Reference & \\
\hline Yes & $42(66 \%)$ & $17(27 \%)$ & $5.3(2.5-11.3)$ & $<0.001$ \\
\hline
\end{tabular}

MMP = matrix metalloprotease.

\section{Results}

Genetic polymorphisms in MMP-1 and MMP-3 are associated with rotator cuff tears, in which individuals with rotator cuff tears have associated genotypes $1 \mathrm{G} / 2 \mathrm{G}$ (patients, 32 of 64 [50\%]; control subjects, 16 of 64 [25\%]; OR, 4.8; 95\% CI, 2.1-11.0; $\mathrm{p}<0.001)$ and $2 \mathrm{G} / 2 \mathrm{G}$ were at great risk (patients, 15 of 64 [23\%]; control subjects seven of 64 [11\%]; OR, 5.2; 95\% CI, 1.8-14.9; p < 0.001) (Table 3), and patients with rotator cuff tears did have a higher proportion of $2 \mathrm{G}$ allele distribution (62 of 128 [48\%] versus 30 of 128 [23\%]; p < 0.001) (Table 4). Patients with the $5 \mathrm{~A} / 5 \mathrm{~A}$ genotype are at greater risk of rotator cuff tears (patients, 15 of 64 [23\%]; control subjects, four of 64 [6\%]; OR, 5.5; 95\% CI, 1.4, 20.9; $\mathrm{p}=0.021$ ), and there was higher $5 \mathrm{~A}$ allele distribution in patients with rotator cuff tears (patients, 68 of 128 [53\%]; control subjects, 52 of 128 [41\%]; $\mathrm{p}=0.045$ ).

Individuals with the haplotype $2 \mathrm{G} / 5 \mathrm{~A}$ were more likely to have rotator cuff tears develop: (patients, 42 of 64 [66\%]; control subjects, 17 of 64 [27\%]; OR, 5.3; 95\% CI, 2.5-11.3; p < 0.001) (Table 3).

Patients with rotator cuff tears reported, in a higher number, the existence of relatives who previously had
Table 4. Distribution of the MMP-1 and MMP-3 allele in rotator cuff tear and control groups

\begin{tabular}{llll}
\hline Alleles & Patients & Control subjects & p Value \\
\hline MMP-1 & & & \\
$1 \mathrm{G}$ & $66(52 \%)$ & $98(77 \%)$ & $<0.001$ \\
$2 \mathrm{G}$ & $62(48 \%)$ & $30(23 \%)$ & \\
MMP-3 & & & 0.045 \\
$5 \mathrm{~A}$ & $68(53 \%)$ & $52(41 \%)$ & \\
$6 \mathrm{~A}$ & $60(47 \%)$ & $76(59 \%)$ & \\
\hline
\end{tabular}

$\mathrm{MMP}=$ matrix metalloprotease.

treatment for rotator cuff tears (19 of 64 [30\%] versus four of 64 [6\%]; OR, 6.3; 95\% CI, 2.0-19.9; $\mathrm{p}=0.001)$.

\section{Discussion}

Rotator cuff tendinopathy is the main cause of shoulder pain [23] with rupture of these tendons occurring in $20 \%$ of the population [43]. The pathophysiology of rotator cuff tear is a multifactorial process and there is evidence that genetic factors may be involved in the etiology of rotator 
cuff tears $[17,24,37,38]$. It is likely that a certain number of genes may be involved in the development of a rotator cuff tear, each one making a small contribution. Complex interactions occur between the proteins, encoded by multiple genes, and the environment in the development of these lesions [35]. Similar to the findings of studies that evaluated patients with lower limb tendinopathies [12, 31], the genetic polymorphism of MMP-1 and MMP-3 is associated with rotator cuff tears.

Our study has some limitations. For a genetic study, the sample with 128 individuals evaluated could be considered small. Studies with larger samples, or in other populations, should be conducted to confirm the association of these polymorphisms with rotator cuff tears. There is a lack of standardization in the imaging examinations used to confirm the integrity of the rotator cuff in asymptomatic individuals; either MRI or ultrasonography was used in the evaluation. However, only Kluger et al. [17] performed rotator cuff imaging to confirm the integrity of the tendon in asymptomatic control subjects, and up to $60 \%$ of patients with rotator cuff tears may be asymptomatic [42]. We also can affirm that ultrasonography had similar sensitivity and specificity to MRI in various studies $[8,19,32]$. We did not assess risk factors for rotator cuff tears such as BMI [15] and dominant arm [31]. These factors that were not evaluated could act as confounding factors in our analysis. However, known risk factors for rotator cuff tears, such as age [39], sex [32], smoking [4], white ethnicity [17], presence of systemic arterial hypertension [14], hypothyroidism [26], professional activity with repetitive efforts with the shoulders [5], and sports with use of the upper limbs [29], did not differ between the two groups we studied, which show that the criteria for obtaining the sample were satisfactory. We conducted an interview to collect data regarding existence of relatives who previously had treatment for rotator cuff tears and presence of tendinopathies in other joints. Patients with rotator cuff tears should probably have better information regarding their personal and familial orthopaedic diseases, leading to a recall bias. As the information was reported by the patient, the diagnoses also may be inaccurate. This may have increased the association between these risk factors and rotator cuff tears.

Our study showed that the genetic polymorphisms of the MMP-1 (rs1799750) and MMP-3 (rs3025058) are associated with rotator cuff tears. The genotypes $1 \mathrm{G} / 2 \mathrm{G}$ or $2 \mathrm{G} /$ $2 \mathrm{G}$ in position -1607 of the MMP-1 gene were risk factors for the development of rotator cuff tears in relation to the individuals with genotype $1 \mathrm{G} / 1 \mathrm{G}$. The individuals with genotype $5 \mathrm{~A} / 5 \mathrm{~A}$ in position -1612 of the MMP-3 gene were more susceptible to rotator cuff tears. The allele $2 \mathrm{G}$ of the MMP-1 polymorphism in position -1607 (rs1799750) increases the transcriptional activity of the gene [33]. This finding provides a molecular basis for the degradation of collagen fibers and increase in MMP-1 activity found in previous histopathology studies of patients with rotator cuff tears $[6,13,18,27,40]$. Allele 5A of the MMP-3 (rs3025058) increases the transcription of this gene [44], and some previous studies reported higher production of MMP-3 in patients with rotator cuff tears in relation to asymptomatic patients $[1,6,27]$. However, the transcriptional activity of the MMP genes is not only associated with polymorphisms of the single nucleotide in the promoter region. The baseline production of MMPs is low, and synthesis is induced by cytokines such as interleukin-1 and tumor necrosis factor, growth factors, and cell-cell and cell-matrix interactions [9]. Unlike our study, Kluger et al. [17], found no differences in the distribution of the MMP-1 and MMP-3 alleles and genotypes. In the case of MMP-1, the polymorphism studied was rs17884110, different from that evaluated by us. In relation to MMP-3, however, the polymorphism evaluated was the same (rs3025058). The lack of agreement between the results may be explained by the smaller number of individuals evaluated, nonpairing between patients and control subjects for age, and known risk factors such as high blood pressure, and racial and genetic characteristics of the population.

Some groups of genetic polymorphisms in adjacent loci on the same chromosome can be inherited in combination; they are called haplotypes. Genetic polymorphisms may act synergistically, increasing the risk for development of tendinous alterations [30]. MMP-1 1G/2G and MMP-3 5A/ 6A SNPs are located on chromosome 11q22.3 and there is a high linkage disequilibrium between these two genes [21]. Individuals with the haplotype $2 \mathrm{G} / 5 \mathrm{~A}$ were more likely to have rotator cuff tears develop.

Initial studies showed that relatives of individuals with rotator cuff tears have a higher risk of having the same disease [16, 36]. Harvie et al. [16] reported that siblings of patients with full-thickness rotator cuff tear had a relative risk of 2.42 (95\% CI, 1.77-3.31) of having such tears in relation to the control group. Tashjian et al. [36] evaluated the genetic predisposition for rotator cuff tears using the Utah Population Database. They observed that second- or third-generation relatives of patients with rotator cuff tears who were younger than 40 years were more likely to experience the same lesion. We found a much higher proportion of patients with family histories of rotator cuff treatment than control subjects with that same history; these findings suggest a familial and genetic predisposition for rotator cuff tears. However, recall bias may have influenced this finding and future cohort studies might more extensively evaluate this association.

Knowledge of the genetic markers related to rotator cuff tears can enable identification of susceptible individuals and increase understanding of the pathogenesis of tendon 
degeneration. Experimental studies have shown that the use of modulators or inhibitors of MMP's activity may influence tissue healing of the rotator cuff repair $[3,10]$. In the future, investigation of other genetic markers could define and standardize all genes at risk for this disease, and thus create adequate conditions for the development of individualized preventive and therapeutic strategies, such as the use of MMP inhibitors in patients susceptible to rotator cuff tears or who underwent repair of these lesions to increase the probability of tendon cicatrization and resistance.

The genetic polymorphism of MMP-1 and MMP-3 is associated with rotator cuff tears. Individuals with haplotype $2 \mathrm{G} / 5 \mathrm{~A}$ were more susceptible to rotator cuff tears in the population studied, and patients with rotator cuff tears have a higher proportion of relatives with the same disease compared with controls subjects.

Acknowledgments Alberto Peters Bambirra MD, Ceci Obara Kurimori MD, and Marcelo Bordalo-Rodrigues $\mathrm{PhD}$ (all from the Department of Radiology, School of Medicine, University of São Paulo, São Paulo, Brazil), performed the MRI or ultrasonography examinations.

\section{References}

1. Abrams GD, Luria A, Carr RA, Rhodes C, Robinson WH, Sokolove J. Association of synovial inflammation and inflammatory mediators with glenohumeral rotator cuff pathology. $J$ Shoulder Elbow Surg. 2016;25:989-997.

2. Aidar M, Line SR. A simple and cost-effective protocol for DNA isolation from buccal epithelial cells. Braz Dent J. 2007;18:148152.

3. Bedi A, Kovacevic D, Hettrich C, Gulotta LV, Ehteshami JR, Warren RF, Rodeo SA. The effect of matrix metalloproteinase inhibition on tendon-to-bone healing in a rotator cuff repair model. J Shoulder Elbow Surg. 2010;19:384-391.

4. Bishop JY, Santiago-Torres JE, Rimmke N, Flanigan DC. Smoking predisposes to rotator cuff pathology and shoulder dysfunction: a systematic review. Arthroscopy. 2015;31:15981605 .

5. Bodin J, Ha C, Petit Le Manac'h A, Sérazin C, Descatha A, Leclerc A, Goldberg M, Roquelaure Y. Risk factors for incidence of rotator cuff syndrome in a large working population. Scand $J$ Work Environ Health. 2012;38:436-446.

6. Castagna A, Cesari E, Gigante A, Conti M, Garofalo R. Metalloproteases and their inhibitors are altered in both torn and intact rotator cuff tendons. Musculoskelet Surg. 2013;97(suppl 1):3947.

7. DE Giorgi S, Saracino M, Castagna A. Degenerative disease in rotator cuff tears: what are the biochemical and histological changes? Joints. 2014;2:26-28.

8. de Jesus JO, Parker L, Frangos AJ, Nazarian LN. Accuracy of MRI, MR arthrography, and ultrasound in the diagnosis of rotator cuff tears: a meta-analysis. AJR Am J Roentgenol. 2009;192:1701-1707.

9. Del Buono A, Oliva F, Longo UG, Rodeo SA, Orchard J, Denaro V, Maffulli N. Metalloproteases and rotator cuff disease. $J$ Shoulder Elbow Surg. 2012;21:200-208.
10. Fox AJ, Schär MO, Wanivenhaus F, Chen T, Attia E, Binder NB, Otero M, Gilbert SL, Nguyen JT, Chaudhury S, Warren RF, Rodeo SA. Fluoroquinolones impair tendon healing in a rat rotator cuff repair model: a preliminary study. Am J Sports Med. 2014;42:2851-2859.

11. Garofalo R, Cesari E, Vinci E, Castagna A. Role of metalloproteinases in rotator cuff tear. Sports Med Arthrosc. 2011;19:207-212.

12. Godoy-Santos A, Cunha MV, Ortiz RT, Fernandes TD, Mattar R $\mathrm{Jr}$, dos Santos MC. MMP-1 promoter polymorphism is associated with primary tendinopathy of the posterior tibial tendon. J Orthop Res. 2013;31:1103-1107.

13. Gotoh M, Hamada K, Yamakawa H, Tomonaga A, Inoue A, Fukuda H. Significance of granulation tissue in torn supraspinatus insertions: an immunohistochemical study with antibodies against interleukin-1 beta, cathepsin D, and matrix metalloprotease-1. $J$ Orthop Res. 1997;15:33-39.

14. Gumina S, Arceri V, Carbone S, Albino P, Passaretti D, Campagna V, Fagnani C, Postacchini F. The association between arterial hypertension and rotator cuff tear: the influence on rotator cuff tear sizes. J Shoulder Elbow Surg. 2013;22:229-232.

15. Gumina S, Candela V, Passaretti D, Latino G, Venditto T, Mariani L, Santilli V. The association between body fat and rotator cuff tear: the influence on rotator cuff tear sizes. J Shoulder Elbow Surg. 2014;23:1669-1674.

16. Harvie P, Ostlere SJ, Teh J, McNally EG, Clipsham K, Burston BJ, Pollard TC, Carr AJ. Genetic influences in the aetiology of tears of the rotator cuff: sibling risk of a full-thickness tear. $J$ Bone Joint Surg Br. 2004;86:696-700.

17. Kluger R, Burgstaller J, Vogl C, Brem G, Skultety M, Mueller S. A candidate gene approach identifies six SNPs in tenascin-C (TNC) associated with degenerative rotator cuff tears. J Orthop Res. 2016 Jun 1. [Epub ahead of print] doi: 10.1002/jor.23321

18. Lakemeier S, Braun J, Efe T, Foelsch C, Archontidou-Aprin E, Fuchs-Winkelmann S, Paletta JR, Schofer MD. Expression of matrix metalloproteinases 1,3 , and 9 in differing extents of tendon retraction in the torn rotator cuff. Knee Surg Sports Traumatol Arthrosc. 2011;19:1760-1765.

19. Lenza M, Buchbinder R, Takwoingi Y, Johnston RV, Hanchard NC, Faloppa F. Magnetic resonance imaging, magnetic resonance arthrography and ultrasonography for assessing rotator cuff tears in people with shoulder pain for whom surgery is being considered. Cochrane Database Syst Rev. 2013;9:CD009020. doi: 10. $1002 / 14651858$.

20. Longo UG, Berton A, Khan WS, Maffulli N, Denaro V. Histopathology of rotator cuff tears. Sports Med Arthrosc. 2011;19:227-236.

21. Lu Z, Cao Y, Wang Y, Zhang Q, Zhang X, Wang S, Li Y, Xie H, Jiao B, Zhang J. Polymorphisms in the matrix metalloproteinase1,3 , and 9 promoters and susceptibility to adult astrocytoma in northern China. J Neurooncol. 2007;85:65-73.

22. Maffulli N, Longo UG, Berton A, Loppini M, Denaro V. Biological factors in the pathogenesis of rotator cuff tears. Sports Med Arthrosc. 2011;19:194-201.

23. Mitchell C, Adebajo A, Hay E, Carr A. Shoulder pain: diagnosis and management in primary care. BMJ. 2005;331:1124-1128.

24. Motta Gda R, Amaral MV, Rezende E, Pitta R, Vieira TC, Duarte ME, Vieira AR, Casado PL. Evidence of genetic variations associated with rotator cuff disease. J Shoulder Elbow Surg. 2014;23:227-235.

25. Munhoz FB, Godoy-Santos AL, Santos MC. MMP-3 polymorphism: genetic marker in pathological processes. Mol Med Rep. 2010;3:735-740.

26. Oliva F, Osti L, Padulo J, Maffulli N. Epidemiology of the rotator cuff tears: a new incidence related to thyroid disease. Muscles Ligaments Tendons J. 2014;4:309-314. 
27. Osawa T, Shinozaki T, Takagishi K. Multivariate analysis of biochemical markers in synovial fluid from the shoulder joint for diagnosis of rotator cuff tears. Rheumatol Int. 2005;25:436-441.

28. Pardo A, Selman M. MMP-1: the elder of the family. Int J Biochem Cell Biol. 2005;37:283-287.

29. Plate JF, Haubruck P, Walters J, Mannava S, Smith BP, Smith TL, Tuohy CJ. Rotator cuff injuries in professional and recreational athletes. J Surg Orthop Adv. 2013;22:134-142.

30. Rahim M, Collins M, September A. Genes and musculoskeletal soft-tissue injuries. Med Sport Sci. 2016;61:68-91.

31. Raleigh SM, van der Merwe L, Ribbans WJ, Smith RK, Schwellnus MP, Collins M. Variants within the MMP3 gene are associated with Achilles tendinopathy: possible interaction with the COL5A1 gene. Br J Sports Med. 2009;43:514-520.

32. Roy JS, Braën C, Leblond J, Desmeules F, Dionne CE, MacDermid JC, Bureau NJ, Frémont P. Diagnostic accuracy of ultrasonography, MRI and MR arthrography in the characterisation of rotator cuff disorders: a systematic review and metaanalysis. Br J Sports Med. 2015;49:1316-1328.

33. Rutter JL, Mitchell TI, Butticè G, Meyers J, Gusella JF, Ozelius LJ, Brinckerhoff CE. A single nucleotide polymorphism in the matrix metalloproteinase-1 promoter creates an Ets binding site and augments transcription. Cancer Res. 1998;58:5321-5325.

34. Schneider S, Roessli D, Excoffier L. Arlequin ver 2.000: a software for population genetics data analysis. Available at: http:// www.cmpg.unibe.ch/software/arlequin/archive/website/software/ 2.000/manual/Arlequin.pdf. Accessed January 26, 2017.

35. September AV, Schwellnus MP, Collins M. Tendon and ligament injuries: the genetic component. Br J Sports Med. 2007;41:241246, discussion 246.

36. Tashjian RZ, Farnham JM, Albright FS, Teerlink CC, CannonAlbright LA. Evidence for an inherited predisposition contributing to the risk for rotator cuff disease. J Bone Joint Surg Am. 2009;91:1136-1142.
37. Tashjian RZ, Granger EK, Farnham JM, Cannon-Albright LA, Teerlink CC. Genome-wide association study for rotator cuff tears identifies two significant single-nucleotide polymorphisms. J Shoulder Elbow Surg. 2016;25:174-179.

38. Teerlink CC, Cannon-Albright LA, Tashjian RZ. Significant association of full-thickness rotator cuff tears and estrogen-related receptor- $\beta$ (ESRRB). J Shoulder Elbow Surg. 2015;24:e3135 .

39. Teunis T, Lubberts B, Reilly BT, Ring D. A systematic review and pooled analysis of the prevalence of rotator cuff disease with increasing age. J Shoulder Elbow Surg. 2014;23:1913-1921.

40. Voloshin I, Gelinas J, Maloney MD, O’Keefe RJ, Bigliani LU, Blaine TA. Proinflammatory cytokines and metalloproteases are expressed in the subacromial bursa in patients with rotator cuff disease. Arthroscopy. 2005;21:1076.e1-1076.e9.

41. Yadav H, Nho S, Romeo A, MacGillivray JD. Rotator cuff tears: pathology and repair. Knee Surg Sports Traumatol Arthrosc. 2009; 17:409-421.

42. Yamamoto A, Takagishi K, Kobayashi T, Shitara H, Osawa T. Factors involved in the presence of symptoms associated with rotator cuff tears: a comparison of asymptomatic and symptomatic rotator cuff tears in the general population. $J$ Shoulder Elbow Surg. 2011;20:1133-1137.

43. Yamamoto A, Takagishi K, Osawa T, Yanagawa T, Nakajima D, Shitara H, Kobayashi T. Prevalence and risk factors of a rotator cuff tear in the general population. J Shoulder Elbow Surg. 2010;19:116-120.

44. Ye S, Eriksson P, Hamsten A, Kurkinen M, Humphries SE, Henney AM. Progression of coronary atherosclerosis is associated with a common genetic variant of the human stromelysin-1 promoter which results in reduced gene expression. $J$ Biol Chem. 1996;271:13055-13060. 